\title{
The Role of Discrete Event Simulation in the Improvement of Manufacturing Systems Performance
}

\author{
P.F. Cunha 1 and R.M. Mesquita 2 \\ 1 EST/IPS - Escola Superior de Tecnologia do Instituto Politécnico de Setúbal \\ Rua Vale de Chaves, Estefanilha, 2900 Setúbal; Portugal; Tel: 65.761621, Fax: 65.721869 \\ 2 Associate Professor - Institute of Materials and Production Tecnologies \\ INETI - Instituto Nacional de Engenharia e Tecnologia Industrial \\ Estrada do Paço do Lumiar; 1699 Lisboa; Portugal; Tel:1.7165181, Fax:1.7166568
}

\begin{abstract}
Many studies have been presented discussing the use of Discrete Event Simulation (DES). This paper presents an overall view on the use of simulation, as a technique to improve manufacturing competitiveness. Considering the several functions that can be identified within a manufacturing system, DES roles will be presented. The benefits of simulation will be demonstrated with two case studies developed in Portuguese industrial companies. A new application area of DES is being developed at IPS and INETI. It will be presented the possibility of using DES, integrated with traditional functions within a company, to support process planning together with manufacturing planning and control, in a simultaneous engineering environment.
\end{abstract}

\section{Keywords}

Discrete Event Simulation, CAPP, MRP/MRPII, MPC and dynamic scheduling.

\section{INTRODUCTION}

In the new global competitive market, industrial companies have been challenged to rethink and adopt new organisational concepts and technologies in order to improve manufacturing system performance. In this new environment the chosen technology and the used management approach are relevant requirements to reach a competitive position. In any type of manufacturing system, the lack of confidence in the expected results when a specific strategy is implemented, has been a restriction for an effective system management. The possibility to know in advance the performances of the system, after the proposed changes have been implemented, will help the managers in decision making. A right and on-time decision could have a major impact in the company's competitive position. Due to the high number of variables and parameters involved in the characterisation of a manufacturing system, it was demonstrated that Discrete Event Simulation is a very useful technique to support the improvement of manufacturing system performance. 


\section{TYPICAL FUNCTIONS WITHIN A MANUFACTURING SYSTEM}

The task of coordinating all the individual activities required to produce, assemble and deliver the product to the customer, involve a multitude of correlated functions together with intensive information exchange. The interaction between the various functions is complex and it is almost impossible to describe all communication channels and central loops of a manufacturing system organisation. Several models are used to represent the interaction between the different functions within a manufacturing system. Based on the model presented by Groover (1987) and the approach developed by Rembold (1993) about the functions of a manufacturing system, figure 1 presents the concept that we will use in our research work. The figure illustrates the information flow and processes that occur throughout the existing functions within a manufacturing system.

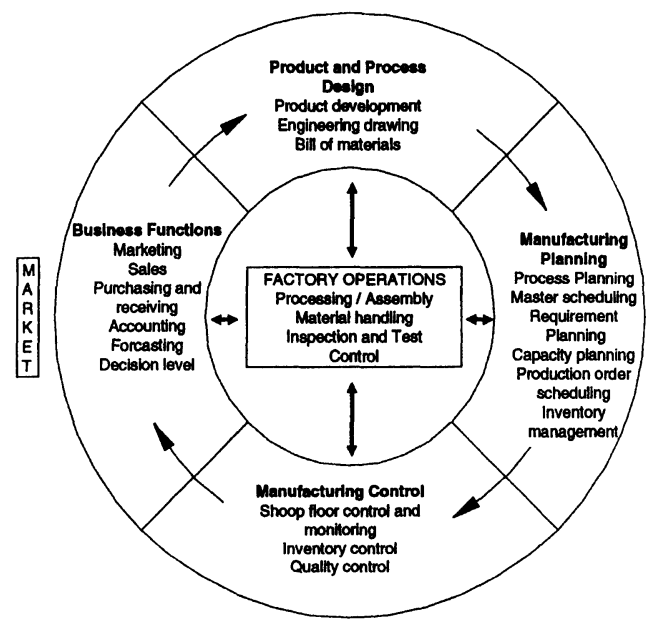

Figure 1 - Information flow and processes in a manufacturing company.

The cycle of events that initiates a new product design often originates in the sales and marketing area. The market behaviour and customer order servicing, must be constantly monitored for customer complaints and new product ideas. Product Design determines the function and design of the product and has a major influence on the manufacturing process to be selected. In this activity, a close cooperation between product and manufacturing process design must be established. With the implementation of some advanced manufacturing technology is possible to generate at this stage, documents which are normally done by manufacturing process planning

The Manufacturing Planning function involve many areas inside the organisation, covering different activities. Manufacturing process planning is one of the activities, where the processes and processing sequences to produce and assembly the product are determined in great detail. The authorisation to produce the product must be translated into the master schedule. It presents a listing of products to be manufactured, when they are to be delivered and the required quantities. A perfectly planned and controlled production system should operate with zero inventory. However, inventory is necessary to deal with some unexpected events that can occur in the manufacturing process.

In order to implement the manufacturing plans the manufacturing control function is concerned with managing and controlling the physical operations in the plant. To some 
extend, inventory control overlaps with shop floor control, in the sense that it is also concerned with inventory. Shop floor control has to follow all parts that are being processed throughout the plant and that must be considered as inventory. Inventory control attempts to generate a proper balance between the danger of a little inventory (and the risk of disruptions) and the expense of having to much inventory. Quality control is a supervisory activity which interfaces with most manufacturing activities .

\section{OVERVIEW OF DES AND SOME APPLICATION AREAS}

As a technique, Discrete Event Simulation has being used more often for different types of manufacturing systems. If appropriately chosen, the simulation system is able to address almost all exercises in a manufacturing company. However it use requires a deep understanding of the manufacturing system, together with the capabilities and operation of the simulation system.

Chase and Aquilano (1989) suggests that Discrete Event Simulation can be used both in the analysis and design of a manufacturing system and in the scheduling of a production system. During the design phase for the implementation of a manufacturing system, simulation focus in equipment and material handling requirements. The output of simulation aids to specify and evaluate the system performance, as well as, to test different control and dispatching strategies. In this context, there is a need for system performance prediction rather than system failure or malfunction assessment after the occurrence of problems. Several studies have been presented showing the successful use of simulation in the design and analysis of Flexible Manufacturing Systems (FMS).

In Scheduling of a production systems, complex decisions must be made that influences global objectives, such as, meeting the delivery due dates and reducing inventory costs. Attempts to consider all of the highly interrelated variables which determine the effectiveness of a particular schedule has not been possible in most manufacturing systems (Grant,1986). Much of the work developed by the activities at the manufacturing planning function are not dynamic, e.g. do not respond to random events that are characteristics of the dynamic behaviour of shopfloor. According to Grant, in practice, production planning is done in many different ways. Probably the most common method of scheduling is achieved with manual techniques. In a more analytical approach, the schedules can be developed using sequencing or dispatching rules that prioritise the jobs waiting for processing. The most widespread planning concept and system is the Material Requirements Planning system (MRP). It was developed, specifically, to manage dependent-demand inventory and scheduling replenishment orders, such as production schedules and purchase orders (Krasewski, 1993). With the extensions to the MRPII, where new modules were added, related to capacity planning and shop floor control with data collection facilities, as well as additional features to cover business financial planning, these techniques prove to be effective for longer term scheduling and order launching. However, there exists a lack of detail that is required for effective day to day production scheduling. As an alternative to these approaches, simulation based scheduling provides an effective tool for shop floor scheduling. Due to the ability of simulation models to predict system behaviour in a greater detail, the use of simulation on a day to day basis, to predict schedule performance and solve problems before they occur, is a natural tendency. 
This discussion stresses the importance of complete integration of the dynamically changing information, as one of the requirements towards dynamic scheduling. According to Larsen (1990), dynamic scheduling is an important way to optimise the plant production in fast changing environments. The dynamic interaction between resources can be captured and analysed with simulation. Simulation models can represent all critical factors to the manufacturing system performance, in as much detail as necessary, depending on the simulation strategy used.

\section{SOME APPLICATIONS OF DES IN PORTUGUESE INDUSTRY}

After the presentation of the functions that exist within a manufacturing company, the above discussion on simulation allowed the identification of the general role of simulation in manufacturing systems improvement. In this section, two industrial applications of simulation in Portuguese companies will be presented to show how it was used to support the managers to plan and to define new strategies for manufacturing system performance improvement. It is presented also other possible application of simulation currently under development, where the traditional tasks of process planning and manufacturing planning and control are integrated with DES.

\section{FNM Case Study}

Fábrica Nacional de Moscavide (FNM) is one of the national defence industries which essentially manufactures light ammunition. FNM is considered to be a medium sized enterprise and the current manufacturing process is based in a similar sequence of operations to each calibre. The existent complexity in the manufacturing process management at FNM is related to the high number of machines involved in the process, together with the constraints that exist in the material flow throughout the manufacturing process (figure 2). The physical distance between sections where each component is manufactured and the specific characteristics of the market for this products impose some relevant rules to manage the manufacturing system. The aim of the project was to investigate how the performances of the manufacturing system at FNM could be improved (Cunha,1993).

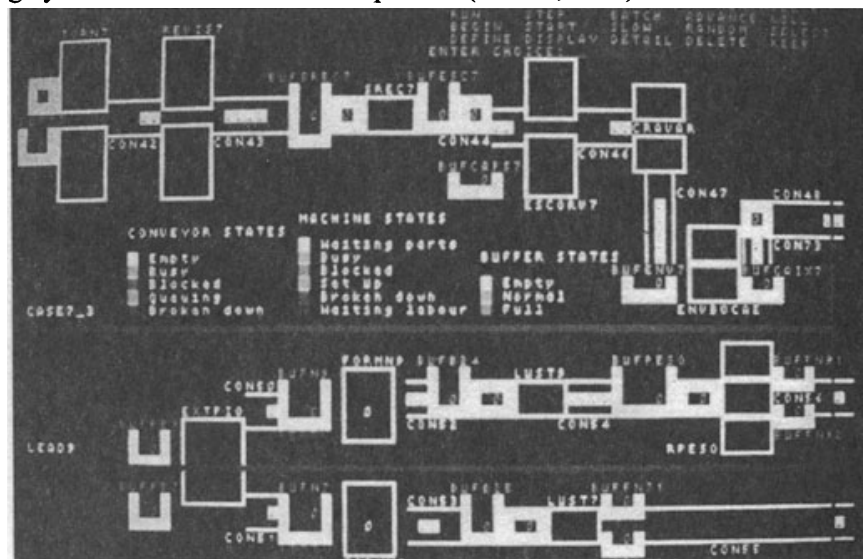

Figure 2 Partial computer model of FNM plant. 
To identify the existing problems in the manufacturing system, the simulation was run with a production plan to satisfy a dummy order. The production plan was developed using the company manufacturing planning and control system. Through this analysis, it was possible to observe the way the system changes and to identify as the main constraints the following ones:

- The level of WIP observed during the manufacturing run is significant. Through the simulation it was shown that by running the model with the developed production plan, high levels of WIP would be produced throughout the manufacturing process.

- Existence of bottlenecks in the process due to operations shared between different products and differences in cycle times. Figure 3 shows the influence of the degreasing operation (operation shared by both calibre).

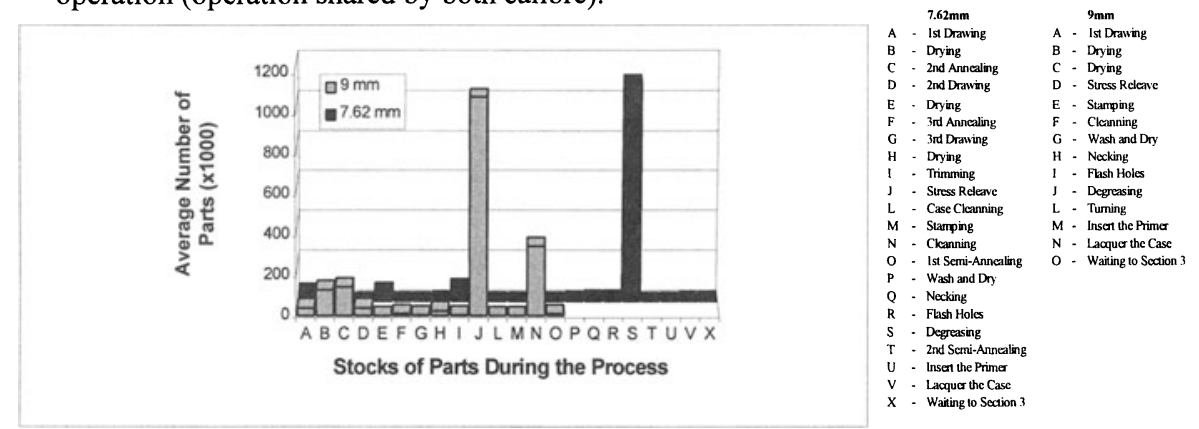

Figure 3 - Average number of parts in stock throughout the pre-case and case manufacturing.

- The rate of breakdowns relative to the system capacity. Throughout the manufacturing system, the machines which have a higher rate of breakdowns were identified through the simulation.

Due to the higher throughput time and cost per unit in the pre-case manufacture, this process was considered critical in the overall manufacturing system. Thus pre-case manufacture was defined as a priority for the simulation study. The improvement of the relevant set of operations can be done either by releasing or removing the bottlenecks or by developing a new production plan. The former solution involves low capital investment and the later requires a new Manufacturing Planning and Control system (MPC) based on the MRP concept. To demonstrate the effect, the new MPC system was integrated with the simulation system. The results obtained from the simulation model when it was tested with the data, reflecting the above mentioned improvements, allowed the identification of different performances. The average reduction in the amount of WIP throughout the manufacturing process was $43 \%$ and $35 \%$ when proposals of a new Degreasing machine and the use of a new approach to develop the production plan were tested in the simulation model. By the introduction of a new machine in the manufacturing process or the usage of a new production plan, a better balance between each operation and between different stages of the manufacturing process was achieved. In each experiment, it was obtained a reduction of $39 \%$ and $61 \%$ in the average time that the purchased raw materials or components took to be transformed or assembled.

The present simulation results allow the managers to have a better understanding of the influence of existing but hidden constraints on the manufacturing system performance. The 
simulation project was a stimulus for the evaluation study about the implementation of a new MPC system. After a few months a decision was taken to purchase a commercial MRP II system.

\section{Merloni Case Study}

MERLONI Electrodomésticos is one of the main Portuguese refrigerators producers. The company have been investing in new equipment and increasing the level of automation. To keep its competitive position MERLONI's manufacturing strategy was defined based on the design of new products and in the development and improvements on manufacturing processes. The managers of the Evaporator Manufacturing System were planning some investments to reduce the manufacturing cost and increase the capacity of the process. Based on a feasibility study of a new system, a simulation project was carried out in order to identify the constraints to manufacture the evaporator and to establish a better balance in the manufacturing process.

During the manufacturing processes definition, it was identified that in a normal production run, models DP240 and DP330 required respectively two and four dedicated assembly tables and a batch size of five units was initially planned. However, during the validation phase, it was identified the possible interest in the evaluation of an alternative system with six assembly tables equally shared by both models. Different combinations were simulated and their effect was analysed. Table 1 shows the planned experiments for each model (DP240/DP330).

Table 1 Simulated experiments and the obtained results (production rate per day)

\begin{tabular}{|c|c|c|c|c|c|c|c|c|}
\hline Experiment & Lot size & Table/Model & Model & Prod. Quanty. & & $\overline{\text { WIP }}$ & & Parts assembled \\
\hline \multirow[t]{2}{*}{ Exp.1 } & 5 & 4 & DP330 & 452 & \multirow[b]{2}{*}{832} & 5 & \multirow[b]{2}{*}{100} & \multirow[b]{2}{*}{932} \\
\hline & 5 & 2 & DP240 & 380 & & 95 & & \\
\hline \multirow[t]{2}{*}{ Exp.2 } & 5 & 4 & DP330 & 248 & \multirow[b]{2}{*}{628} & 2 & \multirow[b]{2}{*}{127} & \multirow[b]{2}{*}{755} \\
\hline & 10 & 2 & DP240 & 380 & & 125 & & \\
\hline \multirow[t]{2}{*}{ Exp.3 } & 5 & 3 & DP330 & 340 & \multirow[b]{2}{*}{703} & 3 & \multirow[b]{2}{*}{120} & \multirow[b]{2}{*}{823} \\
\hline & 5 & 3 & DP240 & 363 & & 117 & & \\
\hline \multirow[t]{2}{*}{ Exp.4 } & 5 & 3 & DP330 & 318 & \multirow[b]{2}{*}{690} & 2 & \multirow[b]{2}{*}{269} & \multirow[b]{2}{*}{959} \\
\hline & 10 & 3 & DP240 & 372 & & 267 & & \\
\hline
\end{tabular}

The simulation runs allowed the observation of different performance for each model according to the production scheduling and the assembly capacity. It was confirmed through the simulation, that the assembly operation was a constraint in the material flow. However the simulation runs showed that if a combination of the number of assembly tables with lot size was considered, it was possible to increase the number of parts assembled. This improvement in the process can be illustrated through the average of WIP build up between the storage system to the end of assembly. As shown in figure 4, in experiment 1 and 4 each model present a low average time in the system which correspond to a better balance obtained between the assembly tables.

The conditions in terms of scheduling and process execution presented in exp.1 and exp.4, show a better output at the end of the simulation run. The balance obtained is also improved, except ahead of coiling operation at the end of the manufacturing process. This bottleneck is 
due to the differences in cycle times but its effect can be reduced with a second shift for this operation.

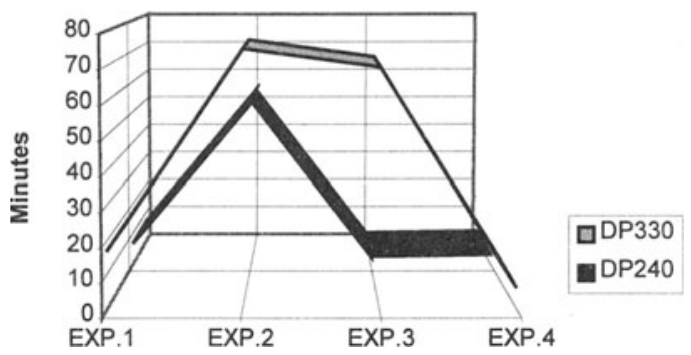

Figure 4 Average time that parts spent between the storage system and the end of assembly tables.

\section{Dynamic Process Planning, Manufacturing Planning and Control: a new application of DES}

With the development and the spread of the CIM concept, the need for the integration of an increasing number of functions was established. Many specialised methods an procedures were developed, enabling each individual system to work more effectively with data generated from the different functions that were identified in figure 1 . The research project under development at INETI and IPS aims the integration of Manufacturing Planning and Control functions (MPC) and Computer Aided Process Planning functions (CAPP) with Discrete Event Simulation tools. This integrated system will be targeted to typical metalworking companies, manufacturing small to medium sized batches.

Process planning does not consider the available resources at the shopfloor. Events in the shopfloor, such as bottlenecks, unavailability of tools and equipment breakdown influences the execution of the manufacturing orders. In this case available pre-developed process plans are no longer adequate. The common procedure is to change the process plan in the shopfloor, which can result in a non optimal plan or the need for the utilisation of alternative sequences of operations and resources. So, the process plan or route sheet, as a static and linear sequence of operations, do not cope with the shopfloor dynamic behaviour. Process planning must be carried out considering the specific machine and tooling capacities, determined by the parts to be manufactured, on an underlying dynamic shopfloor scenario. The real scenario includes simultaneous in progress work, sharing finite resources, scheduled works and unexpected events that affect the production capacity. Process planning systems must interact, in this context, with shopfloor scheduling and monitoring systems, which should be able to know the actual conditions and to modify the production plan using alternative and optimal process plans. Computer aided/assisted process planning (CAPP) functions still rely on a static understanding of the plant. They are process dependent but time invariant functions. With the objective to implement dynamic CAPP systems, through the developments of links between CAPP and MPC, three basic research approaches are being followed: non-linear process planning, closed loop process planning and distributed process planning (Wiendahl, 1995).

Manufacturing planning and control functions are both, process and time oriented and they lead to the use a dynamic model of the production process. The common element between both components is represented today by the process plan, which is available to the MPC system from the CAPP system by means of a data interface (Kuhnle,1994). The role of the 
discrete events simulation system should be the evaluation of the produced schedules where different process plans can be used as a result of shopfloor unexpected occurrences. It can provide managers with both qualitative and quantitative data on the effects of real-time constraints in the manufacturing system performance for decision making. Through DES, a model of the manufacturing process can be developed and analysed, generating data for decision making. Figure 5 illustrates the concept for CAPP/MPC/DES technologies integration.

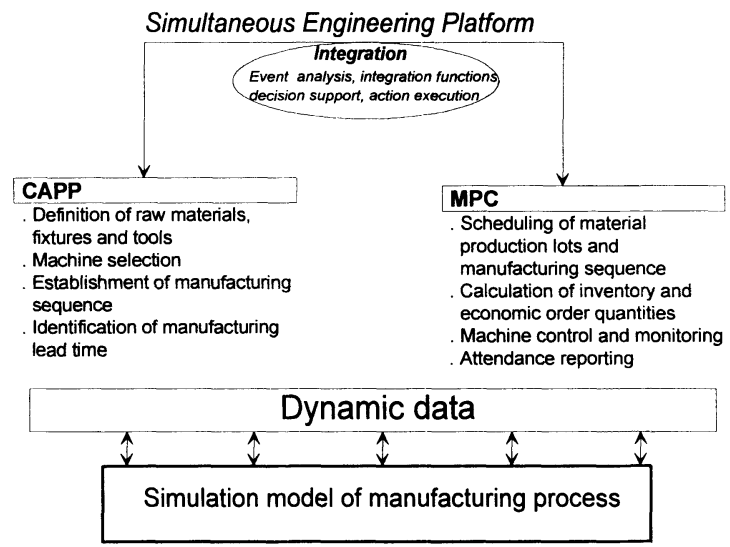

Figure 5 Functional integration of MPC, CAPP and DES techniques.

The creation of process plans using CAPP systems generates the information that is required for work planning in the production process: the necessary resources. The MPC systems are responsible for the complete scheduling and controlling of production process which mainly involves the determination of order quantities and timing for placing orders. The MPC system is based on a description of products (BOM), a description of necessary operations, production resources required (process plan) and dynamic information with regard to demand and the availability of resources. As was shown in section 3, rapidly changing situations in the factory result in difficulties in carrying out the daily schedule. Being this difficulty also related with the relatively isolated way which manufacturing planning and control systems have to operate with the process plan, the ability to communicate effectively between each system allow to create process plans dedicated to problem situations. The simulation can be used to evaluate the new production schedule and provide information about the system performance. Thus the influence of machines, tooling, personnel and other resources can be evaluated through the simulation. All resources have limited capacity so schedules are considered to be realistic and updated.

\section{CONCLUSIONS}

As an engineering tool, Discrete Event Simulation has a significant potential for manufacturing systems design and analysis. New simulation runs can be developed aiming system analysis, using more precise updated and reliable information. The development of a simulation model is not likely to be a once-off exercise. It will go on throughout the planning, commissioning and operation of the manufacturing system. Through the simulation, much of the guess work is discarded from the task of controlling production priorities. Using a 
simulation model, experience can be gained on the appropriate management approach and in the ability to run the real system more effectively. This topic was demonstrated in the simulation of FNM plant for pre-case manufacture. The benefits of introducing MRP II were evaluated through the developed simulation study. Simulation was also successfully used to define and evaluate assembly line configurations, as a function of product design and batch size. The Merloni assembly plant case study demonstrated this ability.

A new field of DES was proposed in this paper. Integrated with other functions of the manufacturing system (CAPP and MPC), DES can have the capability to provide constant and on-line updating data. Production schedules can be simulated in advance to minimise the effects of constraints and provide knowledge about the manufacturing system performance when alternative process plans are required due to shopfloor behaviour. The competitiveness of the company can increase through the improvements and flexibility obtained from simultaneous functionality of each system in an integrated environment.

\section{REFERENCES}

Chase, R.B. and Aquilano, N.J.; Production and Operations Management - A Life Cycle Approach; Irwin; Boston (1989)

Cunha, P.; Discrete Event Simulation for the Improvement of a Manufacturing System; MSc Thesis; Staffordshire University (1993)

Grant H.; Production Scheduling Using Simulation Technology; Proceeding of the 2nd

Conference International on Simulation in Manufactuirng; USA (1986)

Groover M.; Automation Production Systems and CIM; Prentice-Hall; New Jersey (1987)

Krajewski L. and Ritzman L.; Operations Management Strategy and Analysis; Addison Wesly; Massachusetts (1993)

Kuhnle, H.; Braun and Buhring, J.; Integration of CAPP and PPC - Interfusion Manufacturing Management; Integrated Manufacturing Systems; Vol.5; n²; pp.21-27 (1994)

Larsen, E. and Alting, L.; Scheduling of Production Systems by Simulation; 2nd International Conference on Advanced Manufacturing Systems and Technology AMST'90; Italy (1990)

Rembold U., Nnaji B., Storr A.; CIM and Engineering; Addison Wesley; Suffolk (1993)

Wiendahl H., Schmidt B.; A System Solution to Integrated Process Planning and Workshop Scheduling using Manufacturing Alternatives, in Production Engineering, Vol.II/2 (1995)

\section{BIOGRAPHY}

\section{M.Sc. Pedro Filipe do Carmo Cunha}

received his Master degree in Computer Aided Engineering from Staffordshire University in U.K in 1993. Current work is on his Ph.D. at Instituto Superior Técnico (IST-Higher Technical Institute), with the topic in Integration of Production and Process Planning .

\section{Professor, Ph.D. Ruy Manuel Dias Mesquita}

received his Ph.D. in Mechanical Engineering at the Technical University of Lisbon in 1988. He his associate professor in Mechanical Technology at IST since 1991. His research activity has been developed in the area of Production Engineering. At present, he is the director of the Institute of Materials and Production Technologies at INETI-National Institute of Engineering and Industrial Technology. 